\title{
The effects of botulinum toxin A on mechanical and cold allodynia in a rat model of neuropathic
} pain

\author{
[Les effets de la toxine botulique A sur l'allodynie mécanique et l'allodynie au \\ froid chez un modèle de douleur neuropathique chez le rat]
}

Hue Jung Park MD, Yoonki Lee MD, Jaemin Lee MD, Chongmin Park MD, Dong Eon Moon MD

Purpose: Botulinum toxin type A (BoNT-A) has been used to treat many disorders related to excessive muscle contraction, but there are few studies evaluating its effects on neuropathic pain. The aim of this study was to evaluate the analgesic effects of BoNT-A in a rat model of neuropathic pain.

Methods: Male Sprague-Dawley rats were prepared by ligating the left L5 and L6 spinal nerves to produce neuropathic pain. Seventy neuropathic rats were randomly assigned into seven groups. Either normal saline or BoNT-A (10, 20, 30 and 40 $\left.\mathrm{U} \cdot \mathrm{kg}^{-1}\right)$ was administered to the plantar surface of the affected left hind paw, and BoNT-A ( 30 and $40 \mathrm{U} \cdot \mathrm{kg}^{-1}$ ) was administered into the unaffected right paw in order to determine the druginduced systemic effect. Mechanical and cold allodynia were observed at pre-administration, one, three, five, seven and 15 days after drug administration, and were quantified by measuring withdrawal frequencies to stimuli with von Frey filament and $100 \%$ acetone, respectively. Rotarod performance was measured to detect drug-induced adverse motor effects.

Results: The mean minimum withdrawal frequencies to mechanical and cold stimuli were $77 \pm 1 \mathrm{I}$ and $90 \pm 4.5 \%, 46$ \pm 5 and $66 \pm 7 \%, 33 \pm 7$ and $62 \pm 7 \%, 12 \pm 2.9$ and $54 \pm$ $7.3 \%$ with $10,20,30$ and $40 \mathrm{U} \cdot \mathrm{kg}^{-1}$ BoNT-A respectively $(P<$ $0.05)$. Doses of 30 and $40 \mathrm{U} \cdot \mathrm{kg}^{-1}$ BoNT-A resulted in reduced rotarod performance time.

Conclusion: We conclude that peripherally administered BoNT-A reduces mechanical and cold allodynia in a rat model of neuropathic pain.
Objectif : La toxine botulique de type A sert à traiter de nombreux troubles reliés à la contraction musculaire excessive, mais peu d'études ont évalué ses effets sur la douleur neuropathique. Nous voulions évaluer les effets analgésiques de la BoNT-A sur un modèle de douleur neuropathique chez le rat.

Méthode : Les nerfs rachidiens gauches $L 5$ et $L 6$ de rats mâles Sprague-Dawley ont été ligaturés pour produire une douleur neuropathique. Soixante-dix rats ont été randomisés en sept groupes. Une solution salée ou la BoNT-A (I0, 20, 30 et $\left.40 \mathrm{U} \cdot \mathrm{kg}^{-1}\right)$ a été administrée sous la surface plantaire de la patte arrière gauche affectée et la BoNT-A (30 et $40 \mathrm{U} \cdot \mathrm{kg}^{-1}$ ) dans la patte droite intacte pour déterminer l'effet systémique induit par le médicament. L'allodynie mécanique et au froid a été observée avant l'administration du médicament, puis un, trois, cinq, sept et 15 jours après et $a$ été quantifiée par les mesures des fréquences de retrait aux stimuli avec le filament von Frey et $100 \%$ d'acétone, respectivement. La performance au test de la tige tournante a été mesurée pour détecter les effets moteurs indésirables induits par le médicament.

Résultats : La moyenne des fréquences de retrait minimales aux stimuli mécaniques et au froid a été de $77 \pm 1$ I et $90 \pm 4,5 \%$, $46 \pm 5$ et $66 \pm 7 \%, 33 \pm 7$ et $62 \pm 7 \%, 12 \pm 2,9$ et $54 \pm 7,3$ $\%$ avec 10, 20, 30 et $40 \mathrm{U} \cdot \mathrm{kg}^{-1}$ de BoNT-A respectivement $(P<$ 0,05). Les doses de 30 et $40 \mathrm{U} \cdot \mathrm{kg}^{-1}$ de BoNT-A ont réduit le temps de performance au test de la tige tournante.

Conclusion: L'administration périphérique de BoNT-A réduit l'allodynie mécanique et au froid dans un modèle de douleur neuropathique chez le rat.

From the Department of Anesthesiology and Pain Medicine, School of Medicine, The Catholic University of Korea, Seoul, Korea. Address correspondence to: Dr. Dong Eon Moon, Department of Anesthesiology and Pain Medicine, School of Medicine, The Catholic University of Korea, Kangnam St. Mary's Hospital, 505 Banpo-Dong, Seocho-Gu, Seoul, Korea, 137-040. Phone: 82-2-590-1545, 1537; Fax: 82-2-537-1951; E-mail: demoon@catholic.ac.k1

Accepted for publication December 7, 2005.

Revision accepted January 30, 2006.

Competing interests: None declared. 
B OTULINUM toxin type A (BoNT-A) is produced by the bacterium Clostridium botulinum. After binding to the receptors on motor nerve endings, it enters the nerve ending and proteolytically cleaves a protein named SNAP-25; this protein is essential for postdocking and fusion of vesicles prior to the release of acetylcholine. This protein cleavage blocks the release of acetylcholine in the nerve root ending area, which relaxes the muscle. Therefore, BoNT-A has been used to treat many diseases associated with excessive muscle contraction such as strabismus, blepharospasm, hemifacial spasm and cervical dystonia. ${ }^{1}$ In addition, BoNT-A has been shown to relieve the pain induced by myofascial pain syndrome, chronic muscle spasm, low back pain and piriformis syndrome..$^{2-4}$

Although the analgesic effect of BoNT-A has long been considered secondary to its action for muscle relaxation, BoNT-A also affects the release of the neurotransmitters that are involved in pain perception. ${ }^{5,6}$ BoNT-A has recently been shown to have an analgesic effect on the pain induced by formalin and capsaicin, and on chronic facial pain. ${ }^{7-9}$ These reports support that BoNT-A's mechanism for pain reduction is more complex than a simple secondary effect of muscle relaxation.

Recent clinical reports have suggested that BoNTA is effective in treating neuropathic pain associated with diseases such as multiple sclerosis, postherpetic neuralgia, peripheral neuropathy and severe tingling caused by herniation of the cervical vertebrae. ${ }^{10,11}$ However, few controlled studies have examined the effects and adverse reactions of BoNT-A in animal neuropathic pain models. ${ }^{12}$ Thus, we conducted a study to examine the anti-allodynic effects of peripherally administered BoNT-A by observing the withdrawal responses to mechanical and cold stimuli in a rat model of neuropathic pain.

\section{Methods \\ Spinal nerve ligation}

All experimental procedures were approved by the Institutional Animal Care and Use Committee of the Catholic Medical Center. Male Sprague-Dawley rats weighing 180-200 g at the beginning of the experiment were used in this study. The rats were housed in groups of three to four in plastic cages with soft bedding, and they were maintained on a 12:12 hr lightdark cycle. The animals were allowed to adjust to the experimental environment for at least five days before conducting this experiment.

The method of Kim et al. ${ }^{13}$ was used to produce the neuropathic pain model by ligating the left L5 and L6 spinal nerves. After the surgery, rats were allowed to recover for seven days before starting the behavioural tests. Those animals that showed foot withdrawal responses to von Frey filaments (18011 Semmes-Weinstein filament, Stoelting Co., Wood Dale, IL, USA) with an applied bending force of $35.6 \mathrm{mN}$ or less were considered neuropathic, and they were then used in the tests. ${ }^{14}$ Rats that exhibited motor deficiency (such as paw dragging or limping) or those which failed to exhibit subsequent mechanical allodynia were excluded from any further testing.

\section{Drug preparation and administration}

The BoNT-A $\left(\right.$ BOTOX $^{\circledR}$, Allergan, Inc. Irvine, CA, USA) was reconstituted in a $0.9 \%$ saline solution. After it was reconstituted, the solution was stored immediately in a refrigerator and used within two weeks as recommended by Sloop et al..$^{15}$ All the BoNT-A or saline doses were administered as a $40 \mu \mathrm{L}$ bolus in one hind paw. The needle punctured the plantar skin and was placed in the $s c$ space just proximal to the third metatarsal bone. ${ }^{16}$ After randomly assigning the neuropathic rats to groups, either saline or BoNT-A $10,20,30$ or $40 \mathrm{U} \cdot \mathrm{kg}^{-1}$ was administered to the left paw $(n=10$ each). In order to evaluate BoNT-A's systemic effect, BoNT-A 30 or $40 \mathrm{U} \cdot \mathrm{kg}^{-1}$ was injected into the right paw ( $n=10$ each). The injection of the drug took approximately two to three seconds with the rat under $2.0 \mathrm{vol} \%$ enflurane inhaled anesthesia. Anesthesia was ceased immediately after administering the drug, and the subsequent duration of anesthesia was no longer than five minutes.

\section{Behavioural studies}

All behavioural tests were conducted at fixed times ( 1 p.m. to 5 p.m.) in a quiet room by the same person who was unaware of which injected solution had been administered, and the dose that was used. After intraplantar injection, the rats were placed on a metal mesh covered with a plastic dome $(8 \times 8 \times 18 \mathrm{~cm})$ for the assessment of mechanical and cold allodynia. Rats were allowed to adapt to this environment for at least $20 \mathrm{~min}$ before commencement of testing. Mechanical and cold allodynia were assessed both before intraplantar injection, and at one, three, five, seven, and 15 days after injection; after the 15 th day assessment, all rats were then euthanized. All behavioural studies (von Frey, acetone and rotarod) were undertaken after the first postoperative week, and were performed in triplicate. The dosage regimen and observation times were based upon the preliminary experimental results and our previous experiences. 


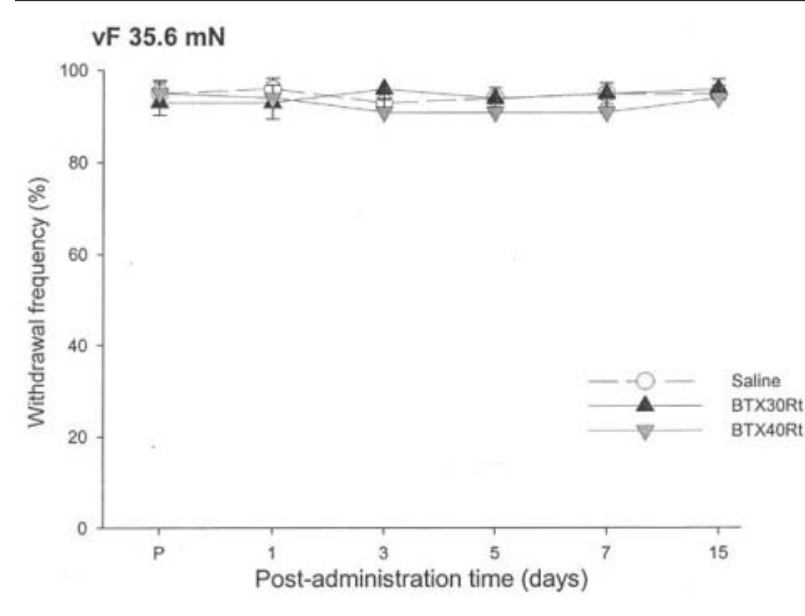

FIGURE 1 Time course of the paw withdrawal frequency to mechanical stimuli after botulinum toxin type A administration to the unaffected right paw in neuropathic rats. Botulinum toxin type A $30 \mathrm{U} \cdot \mathrm{kg}^{-1}$ (BTX30Rt) or $40 \mathrm{U} \cdot \mathrm{kg}^{-1}$ (BTX40Rt) was injected into the unaffected right paw, and the withdrawal frequencies to mechanical stimuli applied with a von Frey filament with $35.6 \mathrm{mN}$ pressure to the plantar surface of the affected left paw were measured in a neuropathic rat. The response frequency was measured before $(P)$ and at days one, three, five, seven and 15 after drug administration. Saline, BTX30Rt or BTX40Rt did not show any difference for the frequencies of withdrawal response to mechanical stimulation of the injured left paw with the $35.6 \mathrm{mN}$ von Frey filament at all observed time points. The results are expressed as mean $\pm \operatorname{SEM}(n=10$ per group).

\section{MEASUREMENT OF MECHANICAL ALLODYNIA}

Mechanical allodynia was administered using a von Frey filament with $35.6 \mathrm{mN}$ pressure. ${ }^{13}$ Additionally, it was administered using a von Frey filament with 148.4 $\mathrm{mN}$ pressure in the preliminary study. Mechanical stimuli were given ten times through the wire mesh to the plantar surface (third metatarsal bone area) of the left hind paw for which the nerve root had been ligated. The mechanical stimuli were administered at intervals of three to four seconds. The occurrence of foot withdrawal in each of these ten trials was expressed as percent withdrawal frequency [(number of paw withdrawals/number of trials $) \times 100]$. Avoidance responses such as lifting, shaking or licking the paw, and running away were regarded as positive responses. ${ }^{17}$
MEASUREMENT OF COLD ALLODYNIA

Cold allodynia was measured as the number of foot withdrawal responses after an application of cold stimuli to the plantar surface of the paw. ${ }^{18} \mathrm{~A}$ drop of $100 \%$ acetone was gently applied to the left heel of the rat with a syringe connected to a thin polyethylene tube. A brisk foot withdrawal response after the spread of acetone over the plantar surface of the paw was considered as a sign of cold allodynia. The testing was repeated five times with an interval of approximately five minutes between each test. The same standard was applied to the positive withdrawals from the acetone as was used for the mechanical stimuli. The response frequency to acetone was expressed as a percent withdrawal frequency [(number of paw withdrawals /number of trials $) \times 100]$.

\section{MOTOR COORDINATION TESTING}

Locomotor function changes in the neuropathic rats were evaluated by conducting rotarod testing (Accelerrotarod for rats 7750, Ugo Basile, Comerio-Varese, Italy). The neuropathic rats were acclimated to revolving drums, and they were habituated to handling in order to ameliorate any stress during testing. Prior to the actual day of the drug testing, the rats were given three training trials on the revolving drums ( $15 \mathrm{rpm}$ ) for two days. The animals that were able to remain on the revolving drum for a minimum of $150 \mathrm{sec}$ were selected for drug testing. The mean of three training runs served as the control performance time. The rotarod performance time was measured at one, three, five, and seven days after the intraplantar injections. Each test was performed three times at five-minute intervals, and the mean values were compared.

\section{Statistics}

Statistical analysis was performed with Sigma-Stat. The percent withdrawal frequency and rotarod performance times were assessed using repeat measures of ANOVA, followed by post hoc Dunnett's tests for multiple comparisons. The results are expressed as mean $\pm S E M$, and a $P$-value $<0.05$ was considered significant.

\section{Results}

Neuropathic pain behaviour developed in $80 \%$ of the experimental rats within two to three days after performing spinal nerve ligation. These animals were healthy in appearance without any complications such as paralysis or limping. During the three-week experimental period, the rats' mechanical allodynia and cold allodynia were consistently maintained. In the preliminary studies, $50 \mathrm{U} \cdot \mathrm{kg}^{-1}$ BoNT-A was injected 


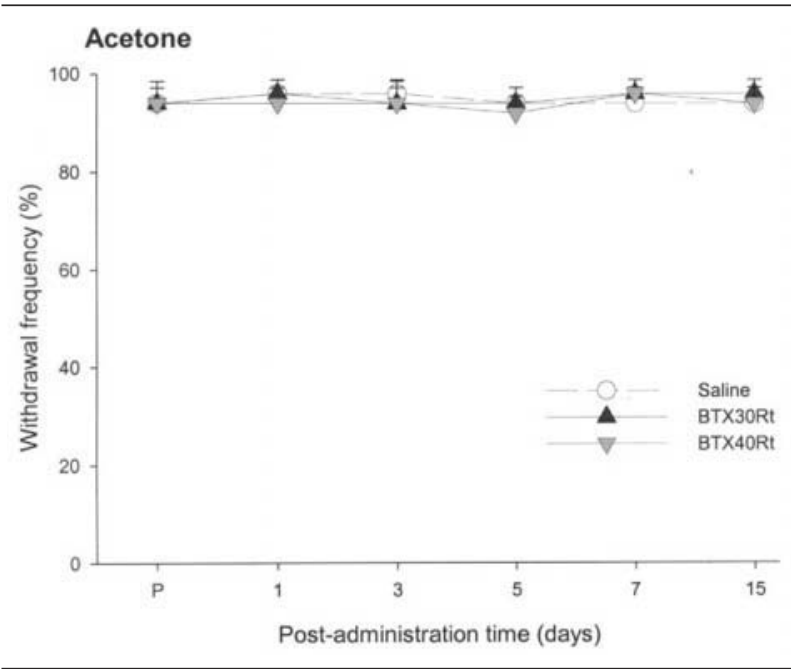

FIGURE 2 Time course of the paw withdrawal frequency to cold stimuli after botulinum toxin type A administration to the unaffected right paw in neuropathic rats. Botulinum toxin type A at $30 \mathrm{U} \cdot \mathrm{kg}^{-1}$ (BTX30Rt) or $40 \mathrm{U} \cdot \mathrm{kg}^{-1}$ (BTX40Rt) was injected into the unaffected right paw, and then the withdrawal frequencies to cold stimuli with $100 \%$ acetone applied to the plantar surface of the affected left paw were measured in neuropathic rats. The response frequency was measured before $(P)$ and at days one, three, five, seven and 15 after drug administration. The frequencies of withdrawal response to acetone were not significantly different at any of the observed time points. The results are expressed as mean $\pm \operatorname{SEM}(n=10$ per group $)$.

into two rats, and both rats died one day after drug administration.

\section{Evaluation of systemic reaction to BoNT-A}

Saline, and BoNT-A doses of $30 \mathrm{U} \cdot \mathrm{kg}^{-1}$ or $40 \mathrm{U} \cdot \mathrm{kg}^{-1}$ injected into the right paw did not show any difference in withdrawal frequencies to mechanical stimulation of the injured left paw when using the von Frey filament with $35.6 \mathrm{mN}$ pressure, at all time points (Figure 1). In addition, the rats' withdrawal frequencies in response to acetone were not significantly different at any time (Figure 2).

\section{Withdrawal frequency to mechanical stimulation WITHDRAWAL FREQUENCY USING THE $35.6 \mathrm{MN}$ VON FREY FILAMENT}

In all animals, the withdrawal frequencies were $94 \%$ or higher at the pre-administration time, and there were no significant differences between test groups. When BoNT-A $10 \mathrm{U} \cdot \mathrm{kg}^{-1}$ was administered, the withdrawal

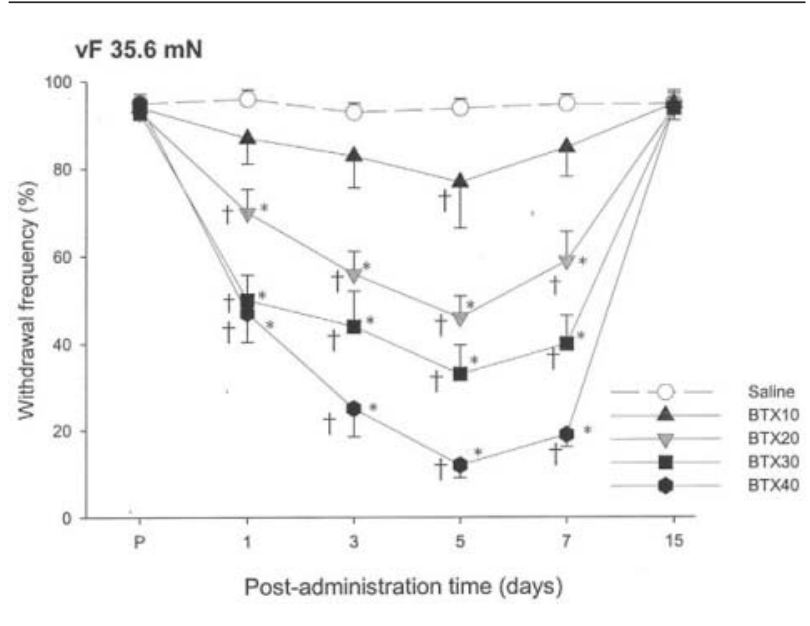

FIGURE 3 Time course of paw withdrawal frequency to mechanical stimuli after botulinum toxin type A administration to the affected left paw in neuropathic rats. Botulinum toxin type A $10 \mathrm{U} \cdot \mathrm{kg}^{-1}$ (BTX10), $20 \mathrm{U} \cdot \mathrm{kg}^{-1}$ (BTX20), 30 $\mathrm{U} \cdot \mathrm{kg}^{-1}(\mathrm{BTX} 30)$ or $40 \mathrm{U} \cdot \mathrm{kg}^{-1}$ (BTX40) was injected into the affected left paw, and then the withdrawal frequencies to a mechanical stimuli applied to the plantar surface of the affected left paw with a von Frey filament with $35.6 \mathrm{mN}$ pressure were measured in a neuropathic rat. Withdrawal frequencies were measured before $(P)$ and at days one, three, five, seven and 15 after drug administration. Results are expressed as mean \pm SEM $\left(n=\right.$ per group). ${ }^{*} P<0.05$ $v s$ saline treated rats by repeated measures of ANOVA and Dunnett's test. $+P<0.05$ vs before administration by repeated measures of ANOVA and Dunnett's test.

frequencies decreased from day one after drug administration. By day five, the withdrawal frequencies were significantly lower in comparison to values before drug administration $(P<0.05)$. However, withdrawal frequencies returned to the original level on day 15 , and were not significantly different from values in the saline group at any corresponding time interval.

When doses of BoNT-A 20, 30 or $40 \mathrm{U} \cdot \mathrm{kg}^{-1}$ were administered, the withdrawal frequencies were significantly lower than those of the saline treated rats; with withdrawal frequencies reaching a nadir on day five. The withdrawal frequencies for the 20,30 or 40 $\mathrm{U} \cdot \mathrm{kg}^{-1}$ doses remained low until day seven $(P<0.05)$, and recovered by day 15 (Figure 3).

WITHDRAWAL FREQUENCY MEASURED AFTER STIMULATION WITH THE 148.4 MN VON FREY FILAMENT Rats treated with BoNT-A $10 \mathrm{U} \cdot \mathrm{kg}^{-1}$ experienced a gradual decrease in withdrawal frequencies, attaining a significant difference on days three and five compared 


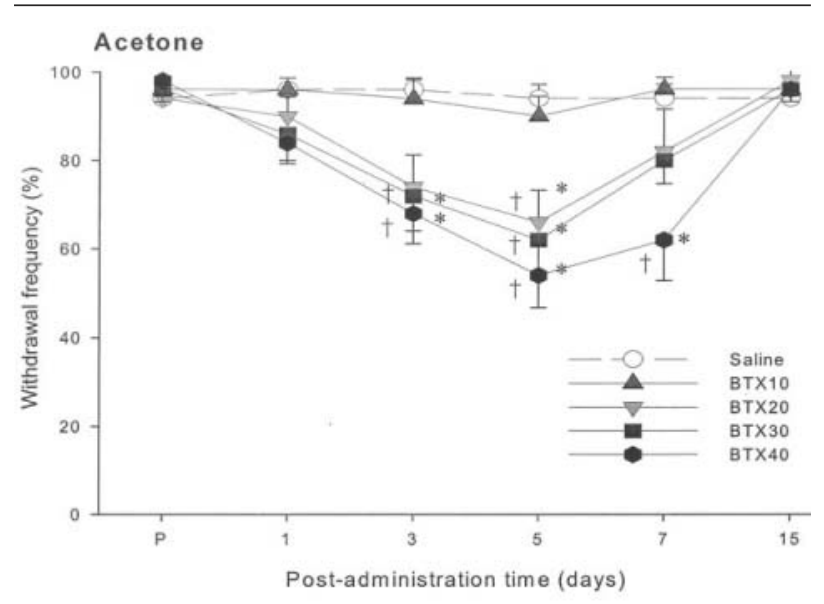

FIGURE 4 Time course of paw withdrawal frequency to cold stimuli after botulinum toxin type A administration into the affected left paw in neuropathic rats. Botulinum toxin type A $10 \mathrm{U} \cdot \mathrm{kg}^{-1}$ (BTX10), $20 \mathrm{U} \cdot \mathrm{kg}^{-1}$ (BTX20), 30 $\mathrm{U} \cdot \mathrm{kg}^{-1}(\mathrm{BTX} 30)$ or $40 \mathrm{U} \cdot \mathrm{kg}^{-1}$ (BTX40) was injected into the affected left paw and the frequencies of withdrawal response to cold stimuli with $100 \%$ acetone applied to the plantar surface of the affected left paw were measured in neuropathic rats. The withdrawal frequencies were measured before $(P)$ and at days one, three, five, seven and 15 after drug administration. Results are expressed as mean $\pm \operatorname{SEM}(n=10 \mathrm{each}) .{ }^{*} P<0.05$ vs saline treated rats by repeated measures of ANOVA and Dunnett's test. $+P<$ $0.05 v s$ before drug administration by repeated measures of ANOVA and Dunnett's test.

with values before drug administration $(P<0.05)$. However, these withdrawal frequencies were not different from those observed in saline-treated rats, and recovered to the baseline level by day 15 . In response to doses of BoNT-A, 20, 30 or $40 \mathrm{U} \cdot \mathrm{kg}^{-1}$ withdrawal frequencies were similar to values observed when using the $35.6 \mathrm{mN}$ von Frey filament $(P<0.05)$.

\section{Withdrawal frequency response to cold stimulation}

Prior to drug administration, all groups showed withdrawal frequencies of $94 \%$ or more following $100 \%$ acetone stimuli. Withdrawal frequencies in rats treated with saline and BoNT-A $10 \mathrm{U} \cdot \mathrm{kg}^{-1}$ were similar. In response to BoNT-A $20 \mathrm{U} \cdot \mathrm{kg}^{-1}$, withdrawal frequencies were lower on day five compared to withdrawal frequencies of the saline treated rats, and responses before drug administration. Following BoNT-A 30 $\mathrm{U} \cdot \mathrm{kg}^{-1}$ withdrawal frequencies were decreased less on days three and five compared to withdrawal frequencies of saline treated rats. BoNT-A $40 \mathrm{U} \cdot \mathrm{kg}^{-1}$

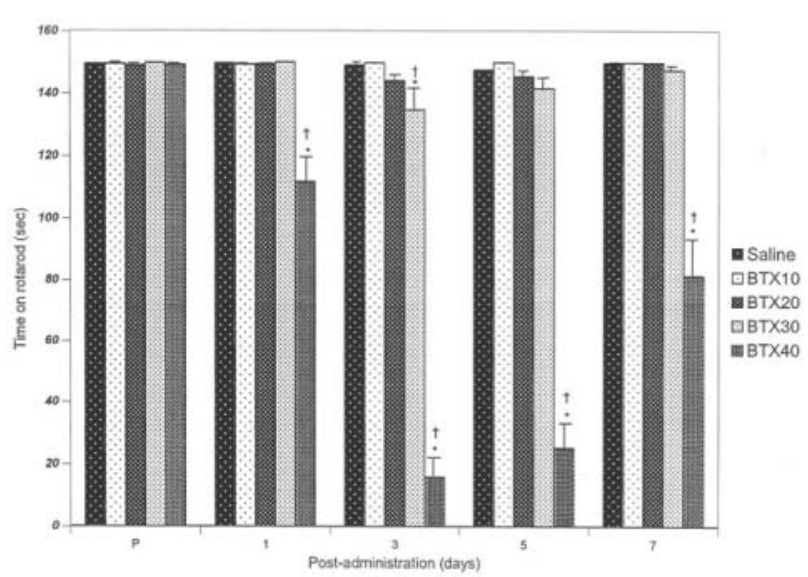

FIGURE 5 Effect of the administration of botulinum toxin type A on the rotarod performance time. The rotarod performance time was measured before $(P)$ and at days one, three, five and seven after drug administration. The rotarod performance time was not reduced by an administration of botulinum toxin type A (BoNT-A) $10 \mathrm{U} \cdot \mathrm{kg}^{-1}$ (BTX10) or $20 \mathrm{U} \cdot \mathrm{kg}^{-1}$ (BTX20). The rotarod performance time was decreased at day three after the administration of BoNT-A $30 \mathrm{U} \cdot \mathrm{kg}^{-1}$ (BTX30). The rotarod performance time was decreased at days one, three, five and seven after administration of BoNT-A $40 \mathrm{U} \cdot \mathrm{kg}^{-1}$ (BTX40). The results are expressed as mean $\pm \operatorname{SEM}(n=10$ each $) .{ }^{*} P<0.05$ ps before administration by repeated measures of ANOVA and Dunnett's test. $+P<0.05$ vs saline treated rats by repeated measures of ANOVA and Dunnett's test.

was associated with lower withdrawal frequencies on days three, five, and seven compared to withdrawal frequencies of the saline treated rats, and withdrawal frequency drug administration $(P<0.05$, Figure 4$)$.

\section{Exercise performance competency}

Compared with the saline treated rats, treatment with BoNT-A 10 or $20 \mathrm{U} \cdot \mathrm{kg}^{-1}$ did not significantly lower the rats' competency for performing the rotarod test. For the BoNT-A $30 \mathrm{U} \cdot \mathrm{kg}^{-1}$ treated rats, their competency for performing the rotarod test decreased significantly to $134.7 \pm 6.2$ on day three $(P<0.05)$. On days five and seven, it recovered gradually to $141.6 \pm$ 5.0 and $147.4 \pm 2.0 \mathrm{sec}$, respectively, which was not significantly different from the statistical cut-off time of $150.0 \mathrm{sec}$. For the BoNT-A $40 \mathrm{U} \cdot \mathrm{kg}^{-1}$ treated rats, their performance competency was $111.7 \pm 11.6$ on day one, and this reached its lowest value of $15.8 \pm$ 4.5 on day three. Although values recovered to 25.2 \pm 10.0 and $81.4 \pm 15.2 \mathrm{sec}$ on day five and seven, 
respectively, it was still significantly lower than those of the cut-off (Figure 5). During the rotarod experiments, there were no rats with closed eyes, and no rat appeared to be sedated. When they were placed on the rotarod, rats walked with the remaining three paws as if the left paw had been paralyzed. They were unable to tolerate the fast speed ( 15 cycles $\cdot \mathrm{min}^{-1}$ ) and a skidding pattern was detected.

\section{Discussion}

This study demonstrates that intra-plantar administration of BoNT-A is associated with a dose-dependent anti-allodynic effect in a rat neuropathic model. The findings suggest that BoNT-A may provide an effective therapeutic option for treatment of neuropathic pain. Considering that diseases causing neuropathic pain respond poorly to traditional analgesic medications including opioids and non-steroidal anti-inflammatory drugs, ${ }^{19}$ an alternative treatment modality for people suffering from this often devastating type of pain is important.

The pain model used in this study was devised by Kim et al. ${ }^{13}$ In this model, ligation of L5 and L6 spinal nerves produced behavioural signs that correspond to the major components of human neuropathic pain: ongoing pain, mechanical and cold allodynia and heat hyperalgesia. The features of this pain model bear similarity to clinical neuropathic pain. ${ }^{13,20,21}$ The acetone test, which was used to assess cold allodynia, was performed by applying $100 \%$ acetone to the sole, and then assessing the pain response resulting from decreased temperature of the sole. ${ }^{18}$

In this experiment, BoNT-A 20-40 U. $\mathrm{kg}^{-1}$, when administered peripherally on the affected rat paw, decreased withdrawal frequencies for more than seven days; with a maximum effect observed on the fifth day. These data suggest that one week may be the maximum effective period of intra-plantar BoNT-A. In contrast, an injection of BoNT-A 30 or $40 \mathrm{U} \cdot \mathrm{kg}^{-1}$ to the unaffected right paw did not elicit an anti-allodynic effect at any point during the study; suggesting an absence of an anti-allodynic action on the left paw as a result of systemic effect at these doses. These results highlight the peripheral applicability of BoNTA as a treatment modality for neuropathic pain with allodynia.

There was no decrease in the withdrawal frequency with BoNT-A $10 \mathrm{U} \cdot \mathrm{kg}^{-1}$ in this experiment. However, Bach-Rojecky et al. ${ }^{12}$ reported that BoNT-A $7 \mathrm{U} \cdot \mathrm{kg}^{-1}$ decreased mechanical hyperalgesia in a neuropathic rat model. This discrepancy is possibly due to differences in the neuropathic pain model and the behavioural tests that were used. Bach-Rojecky et al. ${ }^{12}$ produced neuropathic pain by performing partial sciatic nerve transection, and measured the level of mechanical hyperalgesia by using a paw pressure test.

The most common adverse effect of BoNT-A is muscle weakness or paralysis, and higher doses of BoNT-A can cause death due to respiratory or cardiac failure. ${ }^{22}$ Doses of BoNT-A less than $40 \mathrm{U} \cdot \mathrm{kg}^{-1}$ were used in this experiment because two rats died after receiving BoNT-A $50 \mathrm{U} \cdot \mathrm{kg}^{-1}$ during a preliminary study. This study also examined motor function using the rotarod to assess any potential of impaired coordination or muscle weakness. ${ }^{7}$ In rats receiving BoNT-A $40 \mathrm{U} \cdot \mathrm{kg}^{-1}$, performance competency was significantly decreased from days one to seven. Therefore, in this group of rats, it was difficult to ascertain if the decreased withdrawal frequency to mechanical and cold stimuli resulted from an anti-allodynic effect or a change in locomotor dysfunction. However, these changes in frequency could be distinguished in the other groups. In rats treated with BoNT-A $30 \mathrm{U} \cdot \mathrm{kg}^{-1}$, competency based upon rotarod performance was decreased only at day three after drug administration. In contrast, BoNT-A $30 \mathrm{U} \cdot \mathrm{kg}^{-1}$ was associated with a more prolonged anti-allodynic effect to mechanical stimulation from days one to seven, and also to cold stimulation from days three to seven. These disproportionate responses between muscle weakness and pain relief have been observed in other settings where BoNT-A has been used. When BoNT-A was used to treat a temporomandibular disorder, muscle weakness could be detected two weeks following BoNT-A administration; this muscle weakness recovered thereafter. ${ }^{23}$ However, the analgesic effects continued even after the muscle strength had recovered. This observation suggests that the analgesic effects of BoNT-A can be achieved with little or no muscle weakness. Moreover, even though transient muscle weakness can occur in association with BoNT-A, the analgesic effects may outlast the period of muscle relaxation. Therefore, the anti-allodynic properties of BoNT-A in this experiment were not the result of drug-induced locomotor dysfunction.

Although the mechanism for the anti-allodynic action of BoNT-A is unclear, several theories have been suggested. The analgesic action of BoNT-A has long been considered to be an effect of muscle relaxation..$^{2-4}$ Indeed, abnormal muscle contraction often causes pain in pathological conditions, and inhibition of muscle contraction would be an obvious reason for pain reduction. However, considering the dissociation between observed periods of muscle weakness and pain relief in this neuropathic pain model, it is unlikely that the anti-allodynic action of BoNT-A was due to 
muscle relaxation. BoNT-A has been reported to have an analgesic effect on pain induced by formalin and capsaicin, and also on chronic facial pain. ${ }^{7-9}$ These reports support a mechanism for pain reduction that is more complex than a simple secondary effect of muscle relaxation. BoNT-A is also known to suppress the release of pain by controlling transmitter substance $P$, and it regulates the release of calcitonin gene-related peptide. ${ }^{5,6}$ In a peripheral neuropathic pain model, peripherally released substance $P$ and calcitonin generelated peptide also mediate mechanical hyperalgesia. ${ }^{24}$ Therefore, peripherally administered BoNT-A might affect the release of these mediators and alleviate the hyperalgesia in this pain model. The peripheral glutamate receptor may be involved in mechanical hyperalgesia in a peripheral neuropathic pain model. ${ }^{25}$ It has been suggested that BoNT-A inhibits the release of several neurotransmitters involved in neurogenic inflammation, such as glutamate, thereby reducing peripheral sensitization. ${ }^{26}$ BoNT-A also reduces glutamate release when injected intraplantarly in the rat formalin inflammatory pain model. ${ }^{7}$ Therefore, blockade of the peripheral glutamate receptor by BoNT-A in our neuropathic pain model experiment suggests another mechanism for reducing allodynia.

In conclusion, we have demonstrated that intraplantar injection of BoNT-A effectively reduces mechanical and cold allodynia in a neuropathic rat model. Monitoring for adverse effects such as motor dysfunction would be necessary when administering high doses of this drug.

\section{Acknowledgement}

We thank Dr. S.H. Yoon for his advice in planning this experiment.

\section{References}

1 Mahant N, Clouston PD, Lorentz IT. The current use of botulinum toxin. J Clin Neurosci 2000; 7: 389-94.

2 Porta $M$. A comparative trial of botulinum toxin type A and methylprednisolone for the treatment of myofascial pain syndrome and pain from chronic muscle spasm. Pain 2000; 85: 101-5.

3 Foster L, Clapp L, Erickson M, Jabbari B. Botulinum toxin A and chronic low back pain. A randomized, double-blind study. Neurology 2001; 56: 1290-3.

4 Fishman LM, Anderson C, Rosner B. BOTOX and physical therapy in the treatment of piriformis syndrome. Am J Phys Med Rehabil 2002; 81: 936-42.

5 Welch MJ, Purkiss JR, Foster KA. Sensitivity of embryonic rat dorsal root ganglia neurons to Clostridium botulinum neurotoxins. Toxicon 2000; 38: 245-58.

6 Tarabal O, Calderó J, Ribera J, et al. Regulation of motoneuronal calcitonin gene-related peptide (CGRP) during axonal growth and neuromuscular synaptic plasticity induced by botulinum toxin in rats. Eur J Neurosci 1996; 8: 829-36.

7 Cui M, Khanijou S, Rubino J, Aoki KR. Subcutaneous administration of botulinum toxin A reduces formalininduced pain. Pain 2004; 107: 125-33.

8 Voller B, Sycha T, Gustorff B, et al. A randomized, double-blind, placebo controlled study on analgesic effects of botulinum toxin A. Neurology 2003; 61: 940-4.

9 Borodic GE, Acquadro $M A$. The use of botulinum toxin for the treatment of chronic facial pain. J Pain 2002; 3 : 21-7.

10 Klein $A W$. The therapeutic potential of botulinum toxin. Dermatol Surg 2004; 30: 452-5.

11 Argoff CE. A focused review on the use of botulinum toxins for neuropathic pain. Clin J Pain 2002; $18(6$ Suppl): S177-81.

12 Bach-Rojecky L, Relja M, Lackovic Z. Botulinum toxin type A in experimental neuropathic pain. J Neural Transm 2005; 112: 215-9.

13 Kim SH, Chung JM. An experimental model for peripheral neuropathy produced by segmental spinal nerve ligation in the rat. Pain 1992; 50: 355-63.

14 Jang Y, Kim ES, Park SS, Lee J, Moon DE. The suppressive effects of oxcarbazepine on mechanical and cold allodynia in a rat model of neuropathic pain. Anesth Analg 2005; 101: 800-6.

15 Sloop RR, Cole BA, Escutin RO. Reconstituted botulinum toxin type A does not lose potency in humans if it is refrozen or refrigerated for 2 weeks before use. Neurology 1997; 48: 249-53.

16 Xie J, Yoon YW, Yom SS, Chung JM. Norepinephrine rekindles mechanical allodynia in sympathectomized neuropathic rat. Analgesia 1995; 1: 107-13.

17 Attal N, Jazat F, Kayser V, Guilbaud G. Further evidence for 'pain-related' behaviours in a model of unilateral peripheral mononeuropathy. Pain 1990; 41: 235-51.

18 Choi $\Upsilon$, Yoon $\Upsilon W$, Na HS, Kim SH, Chung JM. Behavioral signs of ongoing pain and cold allodynia in a rat model of neuropathic pain. Pain 1994; 59: 369-76.

19 Arnér S, Meyerson BA. Lack of analgesic effect of opioids on neuropathic and idiopathic forms of pain. Pain 1988; 33: 11-23.

$20 \mathrm{Kim}$ SH, Na HS, Sheen K, Chung JM. Effects of sympathectomy on a rat model of peripheral neuropathy. Pain 1993; 55: 85-92.

21 Wegert $S$, Ossipov $M H$, Nichols $M L$, et al. Differential activities of intrathecal MK-801 or morphine to alter responses to thermal and mechanical stimuli in normal or nerve-injured rats. Pain 1997; 71: 57-64. 
22 Luvisetto S, Rossetto O, Montecucco C, Pavone F.

Toxicity of botulinum neurotoxins in central nervous system of mice. Toxicon 2003; 41: 475-81.

23 Freund B, Schwartz M. Temporal relationship of muscle weakness and pain reduction in subjects treated with botulinum toxin A. J Pain 2003; 4: 159-65.

24 Jang JH, Nam TS, Paik KS, Leem JW. Involvement of peripherally released substance $\mathrm{P}$ and calcitonin generelated peptide in mediating mechanical hyperalgesia in a traumatic neuropathy model of the rat. Neurosci Lett 2004; 360: 129-32.

25 Jang JH, Kim DW, Nam TS, Paik KS, Leem JW. Peripheral glutamate receptors contribute to mechanical hyperalgesia in a neuropathic pain model of the rat. Neuroscience 2004; 128: 169-76.

26 Aoki KR. Evidence for antinociceptive activity of botulinum toxin type $\mathrm{A}$ in pain management. Headache 2003; 43(suppl 1): S9-15. 